\title{
A Study on the Pragmatic Value of Interpersonal Metaphor in Literary Works - A Case Study of Tess of the D 'Urbervilles
}

\author{
Wang Tingting ${ }^{1} \&$ Duan Cheng ${ }^{1}$ \\ ${ }^{1}$ Chengdu University of Technology, Chengdu, Sichuan, China \\ Correspondence: Wang Tingting, Chengdu University of Technology, Chengdu, Sichuan, China. E-mail: \\ 1543426227@qq.com \\ Duan Cheng, Chengdu University of Technology, Chengdu, Sishuan, China. E-mail: 2228951347@qq.com
}

Received: July 27, 2018

Accepted: August 28, 2018

Online Published: October x, 2018

doi:10.5539/ach.v11n1p11

URL: http://dx.doi.org/10.5539/ach.v11n1p11

\begin{abstract}
Grammatical metaphor refers to depicting the same scenes or things in the objective world with different forms of expression. It mainly includes two parts: interpersonal metaphor and ideational metaphor. Interpersonal metaphor is divided into metaphors of mood and metaphors of modality. Metaphors of mood are the transfer from one modal domain to another. The metaphors of modality change from implicit to explicit and reflect in the form of proposition. Language not only has the function of expressing the speaker's personal experience and inner activity, but also can express the speaker's identity, attitude, motivation and his/her inference, judgment and evaluation of things. Therefore, based on the frequency of the use of interpersonal metaphor, the reader can accurately grasp the information exchanged by the speakers. This paper applies interpersonal metaphor to analyze the discourses of the main characters in Tess of the D'Urbervilles by using declarative which is used as command as well as question; interrogative, which is used as command as well as statement, etc. in metaphors of mood and using the subjective explicit as well as objective explicit in metaphors of modality. Through the different expressions of the character discourse, speech function embodied in the discourse is interpreted to help the reader understand the theme of the text more easily, thereby revealing the pragmatic value of interpersonal metaphor in the analysis of literary works.
\end{abstract}

Keywords: interpersonal metaphor, metaphors of mood, metaphors of modality, Tess of the D'Urbervilles, pragmatic value

\section{Introduction}

Metaphor has long been an important research field in linguistics. Grammatical metaphor in the study of metaphor is an important concept of Systemic Functional Linguistics. It was formally proposed by M.A.K. Halliday, the founder of functional linguistics, in his An Introduction to Functional Grammar in 1985. M.A.K. Halliday believes that grammatical metaphor consists of two parts: interpersonal metaphor and ideational metaphor (Liu, 2016). The introduction of grammatical metaphor attracts an increasing number of researchers' attention, and research in this area continues to increase. A domestic scholar He Zhongqing re-analyzes the development of grammatical metaphor theory, clarifies the development of its model and discusses grammatical metaphor related issues as mentioned above (He, 2014). In the past decades, Yan Shiqing mainly discussed the development of grammatical metaphor and its theoretical significance (Yan, 2003). Chang Chenguang attempted to explain the relationship between grammar, grammatical metaphor and experience construction through the core idea of a multi-level system of meaning proposed by systemic functional phonetics (Chang, 2004). However, the research in China is far from reaching a consensus because of the incompleteness and vagueness of M.A.K. Halliday's discussion and the differences not only within Systemic Functional Linguistics but also in other theories such as nominalization, grammaticalization and Cognitive Linguistics. Meanwhile, as a key concept of Systemic Functional Linguistics, although it is still in the developing and improving process, Grammatical metaphor is of great research value. At the same time, functional linguists made a comparison between interpersonal metaphor and ideational metaphor and pointed out that interpersonal metaphor exerted a crucial part in giving information, stating facts and promoting interpersonal exchanges. Furthermore, since the concept of "Grammatical Metaphor" has been quoted by academia, it has been gradually applied to the study of other discourses, such as news reports and literary fictions. Nevertheless, the author has searched all the articles written about interpersonal metaphor on 
CKNI. The result is as follows: these articles contain two types, namely, periodical and thesis. There are twenty-four periodicals written by some of the authors such as Fang (2001), Sun (2009), Zhang and Liu (2011), Yan (2012), Wang (2015), Wang (2015), etc. and ten theses written by other authors such as Shi (2009), Yang (2016) and Guo (2017), etc. Among them, four articles are about the comparative analysis of ideational metaphor and interpersonal metaphor, seven articles analyze the use of interpersonal metaphor in news, business, law, cover letter, politics, and discourse, and seven articles are about the movies, nursery rhymes, speeches, and euphemisms in the use of interpersonal metaphor; twelve explore the relationship between interpersonal metaphor and verbal behavior, cooperation principles, politeness principles and tag questions. However, only four articles are written about the use of interpersonal metaphor in the novel, of which two analyze the translation of the sentences and just two analyze the discourses of the main characters. Therefore, the author of this article applies interpersonal metaphor to the novel and analyzes the discourse of the main characters in it from the aspects of mood and modality, and interprets the speech function embodied in discourses, helping readers to understand the subject of the article more easily, thus revealing the pragmatic value of interpersonal metaphor in the analysis of literary works. Furthermore, this paper gives insights to the following questions:

1) Are there noticeable patterns of interpersonal metaphor in this novel?

2) How do these patterns realized in different expressions?

3) How do these patterns in different expressions interpret the speech function of main characters in this novel?

4) How do the speech functions of interpersonal metaphor reflect the theme of this novel?

5) How does the interpersonal metaphor reveal its pragmatic value in the analysis of literary works?

\section{Grammatical Metaphor}

The concept of grammatical metaphor was first proposed by M.A.K. Halliday, the founder of Systemic Functional Linguistics. Unlike traditional lexical metaphor, M.A.K. Halliday's grammatical metaphor gives priority to the illustration of the word "metaphor" from a functional perspective. M.A.K. Halliday's grammatical metaphor in systemic functional grammar is a supplement to the "lexical metaphor" in traditional grammar. It mainly refers to a linguistic phenomenon in which one grammatical means substitutes for another grammatical means to express a given meaning. M.A.K. Halliday pointed out: "We look at it from another perspective. What we are asking is not how the word is used, but how it is expressed." Consequently, metaphor occurs not only at the lexical level but also at the grammatical level, which led to the concept of grammatical metaphor (Liu, 2016). M.A.K. Halliday classified grammatical metaphor into interpersonal metaphor and ideational metaphor. Interpersonal metaphor is categorized in metaphors of mood and metaphors of modality. Ideational metaphor is manifested through transitivity systems. Since this paper mainly uses the interpersonal metaphor to analyze character discourse, the ideational metaphor is not elaborated.

\section{Interpersonal Metaphor}

Interpersonal metaphor is one of the two meta-functional modes of metaphor. It is a resource for enacting a wider range of social roles and relationships in relation to tenor, allowing interactants to calibrate their interpersonal relations with respect to power (status) and contact (familiarity) (Christian, Matthiessen, Kazuhiro, \& Lin, 2017). It expands the resources of interpersonal meaning through incongruent mapping between interpersonal semantics and lexicogrammar. In this way, the semantic systems of speech function and modality are expanded to provide options in negotiating the relationship between speaker and addressee; for example, He's probably at home vs. I think he's at home; Is he at home? vs. I wonder whether he is at home (Christian, Matthiessen, Kazuhiro, \& Lin, 2017). Therefore, interpersonal metaphor is mainly divided into metaphors of mood and metaphors of modality (Liu, 2016).

\subsection{Metaphors of Mood}

According to M.A.K. Halliday, mood mainly includes two important parts: mood element and mood system. For one thing, mood element consists of two sections: (1) the Subject, which is a nominal group, and (2) the finite operator, which is a verbal group which expresses tense (e.g. is, has) and modality (e.g. can, must) (Halliday, 2016). Meanwhile, the mood system can be seen in Figure 1.

From the introduction mentioned previously, we can see that metaphors of mood mean that the choice of interpersonal meaning is not consistent with its mood. Generally speaking, it is the declarative mood that is used to express statements, the interrogative mood is used to express questions and the imperative mood is used to express commands. However, in actual language use, a verbal function can be expressed in several different moods, and a 
mood can also reflect different verbal functions. This phenomenon of shifting from one mood to another mood is called metaphors of mood (Liu, 2016).

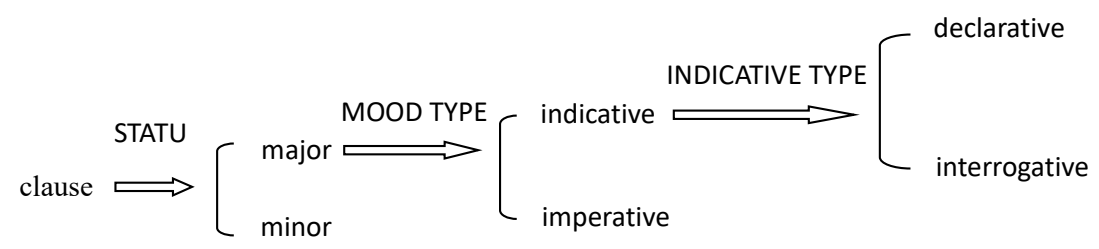

Figure 1. The MOOD system network (M.A.K. Halliday, 2016:23)

\subsection{Metaphors of Modality}

In Systemic Functional Linguistics, the modality system, which can be seen in figure 2, is used by the speaker to express evaluation and judgment of things. In the sentence, it can be expressed in different forms, such as modal verbs, adjectives, adverbs, nouns, and so on. Modality can also be expressed in clauses. M.A.K. Halliday calls this phenomenon metaphor (Hu, Zhu, Zhang, \& Li, 2006).

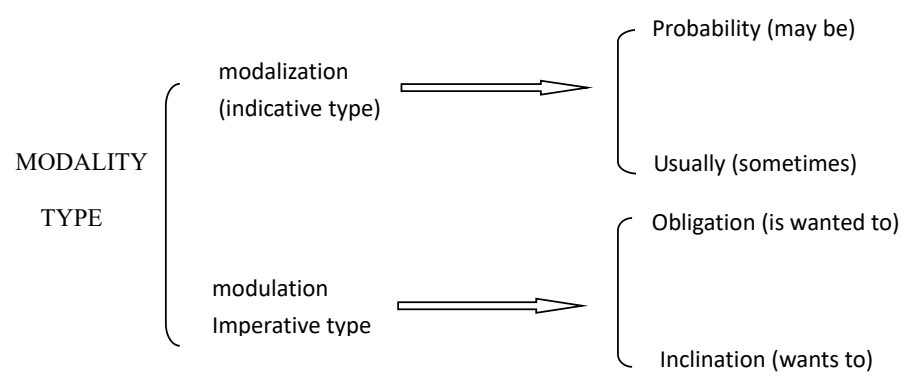

Figure 2. System of type of modality (M.A.K. Halliday, 2016:618)

In addition, modality can be expressed from both subjective and objective perspectives. The basic distinction that determines how each type of modality will be realized is the orientation: that is, the distinction between subjective and objective modality, as well as between the explicit and implicit variants (Halliday, 2016). Halliday (2000) classified the orientation into subjective and objective orientations. That is, the modality component can indicate the subjective attitude or willingness of the speaker to the proposition, as well as the possibility or inevitability of an objective existence. At the same time, both subjective and objective orientations are explicit and implicit. This form contains the following four modality orientations: subjective explicit, subjective implicit, objective implicit and objective explicit.

Provided that the speaker wants to articulate his or her opinion about the likelihood of something or highlight his or her point of view, he or she will choose subjective explicit. If the speaker wants to hide his or her real intentions and make his or her point become an inherent fact, the objective implicit form is chosen. Therefore, in M.A.K. Halliday's view, subjective explicit and objective explicit belong to metaphors of modality.

\section{Introduction of Tess of the D'Urbervilles}

Thomas Hardy, a famous British novelist and poet, is also known as the "father of modern poetry" in Britain in the 20th century. Among Thomas Hardy's works, Tess of the D'Urbervilles is the most important masterpiece and one of the greatest works in English literature. This work is written after the industrial revolution. Affected by the industrial revolution, the capitalist ideology impacts the old ways of thinking. The extensive use of agricultural machinery also accelerates the deterioration of the impoverished peasant economy. Landlords and wealthy peasants exploit the impoverished proletarians more cruelly. Therefore, people who live in this period also has complex characters. Since the introduction of this novel, many domestic scholars have translated the original text. Some scholars have also evaluated the main characters of the novel when they preface the translation. Zhang Ling believes that Tess's father is born lazy and ignorant; her mother's mind is simple and she admires vanity; Tess reflects on the beauty of rural girls who she considers simple, kind, and strong. Angel Clare has "advanced thinking and good intentions" in love and marriage. But when the true test comes, he is unaware of insisting the training he has received from childhood, or he is a slave of prejudice as well as an accomplice (Hardy, 1984/1999). Zheng Damin deems that Tess's father and her mother are shortsighted; Tess has a sense of responsibility and filial 
piety; Claire has the characteristic of disdain in obeying traditional conventions and habits. He is the true love of Tess, so he can't accept the fact that Tess is raped (Hardy, 1984/2006). Zhao Zhixin holds that Tess pursues freedom and yearns for happiness; Alec is hypocrite and lecher (Hardy, 1984/2013).

It is precisely because of the complexity of the characters in the novel that readers must truly understand the subject of the article and need to inquire about it at a deeper level. As a result, the following analysis will use interpersonal metaphor to interpret the character discourses in the novel, so that the readers may have a better understanding of it.

\section{Data Analysis}

As it is mentioned earlier, interpersonal metaphor is classified into metaphors of mood and metaphors of modality. This paper has listed all the metaphors of mood and metaphors of modality used by the main characters in the novel and they are shown in Table 1.

Table 1. Numbers of Metaphors of Mood and Metaphors of Modality Used by Major Characters

\begin{tabular}{cccc}
\hline Main Characters & Metaphors of Mood & Metaphors of Modality & Total \\
\hline Tess' father & 3 & 8 & 11 \\
Tess' mother & 8 & 13 & 21 \\
Tess Durbeyfield & 22 & 82 & 104 \\
Alec D'Urberville & 9 & 21 & 30 \\
Angel Clare & 12 & 29 & 41 \\
Total & 54 & 153 & 207 \\
\hline
\end{tabular}

From Table 1, it can be seen that the main characters of the novel use much more metaphors of mood than metaphors of modality, which shows that the author of the novel mainly writes from the perspective of the characters themselves, allowing them to express their own opinions, which reflects their psychological thinking and highlights their distinctive personality.

Since there are many metaphors of mood and metaphors of modality involved in the novel, this paper will analyze only several typical characters' discourses in the novel so as to deeply analyze the personality and psychological activities of the main characters.

Meanwhile, metaphors of mood and metaphors of modality can be achieved by many forms. The author also counts the different forms expressing the intention of major characters in this novel. The results are shown in Table 2 and Table 3.

Table 2. Numbers of Forms of Metaphors of Mood Used by Major Characters

\begin{tabular}{|c|c|c|c|c|c|c|}
\hline Main characters & $\begin{array}{c}\text { declarative } \\
\text { used as } \\
\text { command }\end{array}$ & $\begin{array}{l}\text { declarative } \\
\text { used } \\
\text { as question }\end{array}$ & $\begin{array}{c}\text { Interrogative } \\
\text { used as } \\
\text { statement }\end{array}$ & $\begin{array}{c}\text { Interrogative } \\
\text { used as } \\
\text { command }\end{array}$ & $\begin{array}{l}\text { Imperative used } \\
\text { as question }\end{array}$ & Total \\
\hline Tess' father & 2 & 1 & 0 & 0 & 0 & 3 \\
\hline Tess' mother & 2 & 3 & 2 & 1 & 0 & 8 \\
\hline Tess Durbeyfield & 5 & 3 & 9 & 4 & 1 & 22 \\
\hline Alec D'Urberville & 5 & 1 & 2 & 1 & 0 & 9 \\
\hline Angel Clare & 2 & 3 & 6 & 1 & 0 & 12 \\
\hline Total & 16 & 11 & 19 & 7 & 1 & 54 \\
\hline
\end{tabular}

Table 3. Numbers of Forms of Metaphors of Modality Used by Major Characters

\begin{tabular}{cccc}
\hline Main characters & Subjective explicit & Objective explicit & Total \\
\hline Tess' father & 8 & 0 & 8 \\
Tess' mother & 12 & 1 & 13 \\
Tess Durbeyfield & 82 & 0 & 82 \\
Alec D'Urberville & 21 & 0 & 21 \\
Angel Clare & 29 & 0 & 29 \\
Total & 152 & 1 & 153 \\
\hline
\end{tabular}


From table 2 and 3, we can see that numerous metaphors of mood are used by major characters in this novel to express their mood, which is able to help readers better interpret their rich psychological activities. Simultaneously, metaphors of modality are used frequently especially subjective explicit. The intention of the author is to let the characters independently express their different thoughts. Both of the two metaphorical forms can help readers clearly understand the theme of this novel and the specific application will be presented in the following part.

\section{Application of Interpersonal Metaphor in Tess of the D'Urbervilles}

After explaining the meaning of metaphors of mood in previous part, in the following Table 4 demonstrates some examples to help the reader understand its application more easily.

Table 4. Examples of Metaphors of Mood (Halliday, 2016)

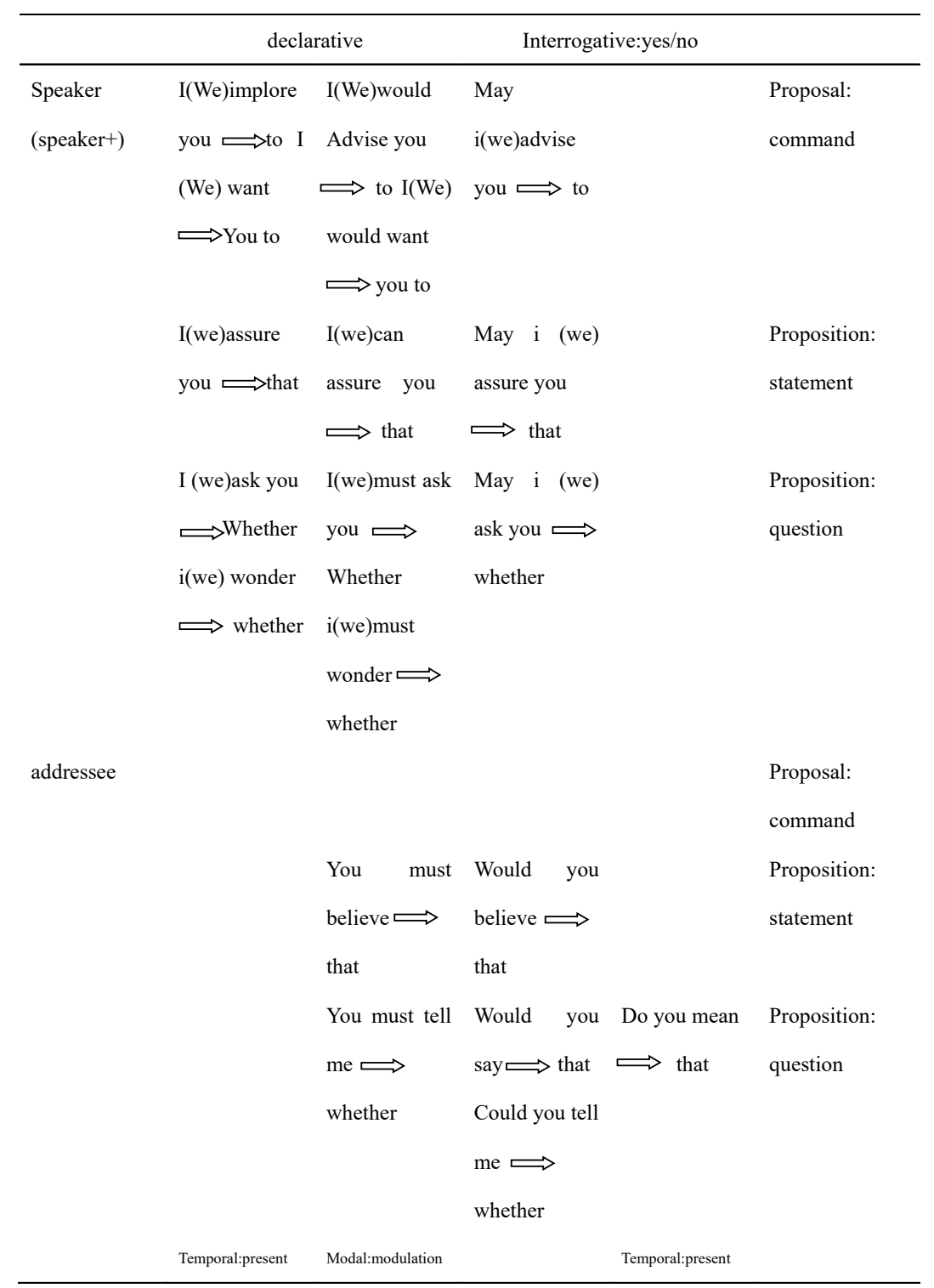

\subsection{Metaphors of Mood}

The following typical examples are selected in the original novel to help us use metaphors of mood accurately in literary works. For more examples please refer to Appendix 1 Metaphors of mood and Appendix 2 Metaphors of modality. 


\subsubsection{Declarative Used as Command}

The declarative mood is usually used by speakers to make a statement, however, in actual communication, it is also used to make a command to let the tone of speaker sound more polite and euphemistic. This is reflected in the typical examples listed below.

Example one:

After the family persuade Tess, she promises to claim kin. Before she left, her father says the following words:

'I don't quite like my children going away from home,' said the haggler. 'As the head of the family, the rest ought to come to me.' (Hardy, 1984:65)

In the above underlined sentence, the mood element of the declarative sentence is constrained in terms of subject person and the finite operator. Subject in the underlined sentence is "I", and the finite operator is temporal "don't quite like", the speech function of this sentence is construed as a proposal "I don't quite like", which is used as a projection nexus between the metaphorical form and congruent form of this sentence. Its congruent form is the clause "My children shouldn't go away from home". Therefore, this declarative sentence is treated as imperative to express command. It can be seen that the two different forms express the same meaning; hence, it is a metaphor of mood. "I don't quite like" as the mood element in its metaphorical form is typically a milder version of a command showing Tess' father's emotional inclination to make the listener feel more comfortable. We can also feel from Tess's father's tone that his character is mild. At the same time, combined with the context of the sentence, it can also be seen that Tess's father has the highest status in the family, and he has the most discourse power, reflecting that the Victorian period is still dominated by patriarchal society.

Example two:

Alex takes Tess back to work. On the way, he deliberately accelerates the speed of the carriage to find opportunity to kiss Tess. Though he succeeds, Tess reluctantly wipes the place where she has been kissed. Alex is very unhappy and says the following words:

'You shall be made sorry for that!' he resumed, his injured tone still remaining, as he flourished the whip anew. (Hardy, 1984:79)

The same as the first example, the subject person in the underlined declarative sentence is the word "You" and its finite operator is modulation, more specifically "shall", the speech function is construed as a proposal "You shall be", which is the projection nexus. Its congruent form is "Made sorry for that". Consequently, the meaning of this sentence is also combined with two different forms to express the same function 'command', which is a metaphor of mood. Here the subjects are people being held responsible for complying with the 'command', and this embodies the obligation for Tess to do things. Without doubt, Alex in this sentence is the controller. 'You shall' in the declarative sentence is more stronger than its congruent form which does not mean that his temperament is more gentle and he treats Tess with more kindness, but it is in stark contrast to the fierceness behind the fictional plot of Alec's tarnishing of Tess, and even more it reflects his hypocrisy. It can also be seen from Alex's relatively strong tone that he and Tess are not from the same social class. Alex, who is from an upper social-economic clan, is much more superior to Tess in social identity, and is even more dominant in tone.

Example three:

Tess is very sad after being raped. When she returns home, she not only doesn't get her mother's understanding and comfort but is reproved instead:

'You ought to have been more careful if you didn't mean to get him to make you his wife!' (Hardy, 1984:116)

In the underlined example, it is a declarative sentence. Its subject is "You" and the finite operator is modulation, namely, "ought to", the speech function of this sentence is proposal. Its congruent form is "Be more careful if you didn't mean to get him to make you his wife". In this example, the declarative sentence realizes a kind of command which functions as a reproach. Tess in this sentence still inclines to do things that her mother hopes. From the tone of Tess's mother, it can be seen that she doesn't look at the problem from her daughter's standpoint. Her daughter encounters extremely terrible things. She doesn't comfort her daughter but complain about it. It is closely related to the beginning of this novel that Tess' parents forces her to claim kin without really knowing about Alex. It also leads to Tess' current tragedy. 


\subsubsection{Declarative Used as Question}

Example one:

Tess knows that her father who is in poor health drinks again, she feels very angry so she says the following sentence to her mother:

'O my God! Go to a public-house to get up his strength! And you as well agreed as he, mother!' (Hardy, 1984:27)

In the underlined sentence, the speech function is construed as a proposition which is realized by a clause nexus of projection "you as well agreed as he". Its subject is "You" and the finite operator is "agreed". Its congruent form is "Why did you as well agree as he, mother?" Both of the different forms express Tess' complaint about her mother. In this sentence, Tess uses declarative rather than interrogative to express a question, which can be seen that although she is dissatisfied with her mother's behavior, she doesn't express it directly. Her speech is more euphemistic which reflects her respect for her mother. At the same time, from her complaining tone, the reader can also see that she is worried about her father's health and is filial to her father. This is directly connected with her promise to her parents to claim kin and eventually leads to her tragic ending.

Example two:

\section{'...But she can make him keep her if he's married her?' (Hardy, 1984:367)}

Just as in the previous example, the meaning of the underlined sentence is also combined by two different forms, that is its metaphorical form and congruent form to express question and its function is to express complaint and blame. The congruent form of this sentence is "Why she cannot keep her if he's married her?" The subject of this sentence is "she" and the finite operator is modalization "can". From the tone of Tess's father, the reader can see that he uses declarative sentences instead of interrogative sentences to express his dissatisfaction, and the effect is more euphemistic, which is consistent with his lazy character in the text. At the same time, as the head of the family, Tess's father, after knowing that his daughter is abandoned, doesn't rationally analyze the cause of the incident, instead he makes up his own mind, which makes a comparison with Tess's braveness and responsibility. In stark contrast to her character, her parents' greed and selfishness lead directly to Tess' tragedy.

\subsubsection{Interrogative Used as Statement}

After knowing about Tess's tragic past, Angel's attitude toward Tess gradually becomes cold. Tess can't accept this change, so she says the following sentence:

\section{'...Then how can you, O my own husband, stop loving me?' (Hardy, 1984:327)}

In the underlined sentence, the speech function is construed by a proposition "how can you stop loving me". Its congruent form is"You cannot, O my own husband, stop loving me." The two different forms express a statement. The subject in this sentence is "you" and the finite operator is modalization "can". The presence of the mood element expands the potential for negotiation, at the same time, Tess prefers to use the interrogative rather than declarative, a statement reflects the way in which Tess wants to resonate with her husband through a questioning approach. Meanwhile, when facing the different attitudes of her husband, Tess is also very disappointed and sad, which reflects her deep love for her husband. Therefore, the plot that Tess kills Alex for her lover in the end of this novel can be forgiven.

Example two:

After Tess confesses to her husband, she is rejected by him, so she can only return to her family for the time being. Thinking about her current situation, Tess sighs with emotion:

\section{'Who would you think I was Mrs. Angel Clare!' she said. (Hardy, 1984:398)}

In the underlined sentence, although Tess uses an interrogative question, she doesn't express a question. She only wants to express a statement that mirrors her inner heart. The speech function of the interrogative sentence is construed by a proposition"Who would you think", of which the congruent form is "Nobody would think I was Mrs. Angel Clare!" she says. The two different statements express the same function 'disappointed and helpless'. The subject in this sentence is "you" and the finite operator is "think". From the text, it can be seen that Tess is talking to herself. From the questioning tone she uses, it can be seen that the emotion she wants to express is stronger than the declarative sentence, which reflects her current helplessness and despair. 


\subsubsection{Interrogative Used as Command}

Example one:

Tess is cheated and returns home with disappointment and sadness . Her mother thinks she is going home to get married, but Tess says no, and she won't marry Alex. Her mother doesn't ask the reason but immediately start to complain:

'...Why didn't ye think of doing some good for your family instead o' thinking of doing yourself?' (Hardy, 1984:115)

In the above underlined sentence, the speech function is construed as a proposition "Why didn't ye think of", its subject is "ye" and finite operator is the verb phrase "didn't think, although Mrs. Durbeyfield uses the interrogative, she expresses command whose function is to express her reproach to her daughter. Its congruent form is "You shouldn't think of doing yourself and didn't doing some good for your family". In this sentence, we can see that Mrs. Durbeyfield uses interrogative to express her reproach. Her tone also reflects her selfishness and greed because she doesn't consider the situation from her daughter's standpoint.

Example two:

Angel confesses his past bad experience to Tess, Tess forgives him, but Tess doesn't explain her past to Angel, because she is afraid of losing Angel, so she can't accept Angel's courtship. Angel doesn't understand her behavior, so there is the following sentence:

\section{'...The secret is out, so why should you any longer refuse me?' (Hardy, 1984:274)}

The same as in the previous example, in this underlined interrogative sentence, Angel uses the interrogative but he doesn't want the listener's reply. He only wants to express his ideas. The speech function of this sentence is construed as a proposition "why should you". Its congruent form is "Don't refuse me any longer". Its subject is "you" and the finite operator is modalization "should" which is just a probability. The presence of the mood element refers to negotiation. The use of the interrogative makes the mood of this sentence milder than its original one which can be seen that Angel really likes Tess and can't bear to hurt her, so his tone is milder. At the same time, this also contrasts with the latter part of the novel, when Angel knows Tess's past. The attitude of indifference is in stark contrast, so that he and Tess will have a sad ending.

\subsubsection{Imperative Used as Question}

Example one:

Tess comes back from the outside and knows that her father goes outside to drink again. She is angry and says the following to her mother:

\section{'Get up his strength!' said Tess impetuously, the tears welling to her eyes. (Hardy, 1984:27)}

In the above underlined sentence, Tess uses an imperative sentence to express her anger. The speech function is construed as a proposition "Get up his strength", its congruent form is "Does he just get up to his strength?", here, the subject is "his" and the finite operator is the verb phrase "get up". From this sentence, we can see that Tess is so worried about her father's health that she can't bear to see her father drinking again. The mood of this imperative sentence is stronger than the interrogative so it can express Tess' fierce emotions properly. From Tess's tone, the reader can also see that she complains and reproaches her mother for letting her father drink alcohol. At the same time, we can also see that as the head of the family, Tess is very sensible and loves her family, so she promises her parents to claim kin at the end of the novel, which eventually led to her tragic end.

From the above examples, the reader can see that one speech function can be achieved by different moods, for example, a declarative clause can be used to express a command and an interrogative question can also be used to express a statement and a command. Among them, the mood of the imperative is stronger than the declarative statement, the use of the interrogative can attract a listener's attention much more easily than the other two moods. Hence, if the speaker wants to emphasize his/her ideas in the imperative, declarative can be chosen, however, if he/ she wants to resonate with the listener, the interrogative is a better choice. All in all, after analyzing the above examples in this novel, the complex characteristics of the main characters are clearly presented in the reader' minds and this will help the reader easily understand the writer's standpoint. It identifies that the speech function of metaphors of mood can further explain the theme of this novel.

\subsection{Metaphors of Modality}

Similar to metaphors of mood, some examples of metaphors of modality can be found in Table 5 to help the reader better understand their application after explaining the meaning of them in the previous part. 
Table 5. Examples of metaphors of modality (Halliday, 2016:620)

\begin{tabular}{|c|c|c|c|c|}
\hline & $\begin{array}{l}\text { subjective } \\
\text { explicit }\end{array}$ & $\begin{array}{c}\text { subjective } \\
\text { implicit }\end{array}$ & $\begin{array}{c}\text { objective } \\
\text { implicit }\end{array}$ & $\begin{array}{c}\text { objective } \\
\text { explicit }\end{array}$ \\
\hline $\begin{array}{l}\text { Modalization: } \\
\text { probability }\end{array}$ & $\begin{array}{l}\text { I think (in my opinion) Mary } \\
\text { knows }\end{array}$ & Mary'll know & $\begin{array}{c}\text { Mary probably } \\
\text { knows(in all probability) }\end{array}$ & $\begin{array}{l}\text { It's likely that Mary } \\
\text { knows(Mary is likely to) }\end{array}$ \\
\hline $\begin{array}{l}\text { Modalization: } \\
\text { usually }\end{array}$ & & $\begin{array}{l}\text { Fred'll sit quite } \\
\text { quiet }\end{array}$ & Fred usually sits quite quiet & $\begin{array}{l}\text { It's usual for Fred to sit quite } \\
\text { quiet }\end{array}$ \\
\hline $\begin{array}{l}\text { Modulation: } \\
\text { obligation }\end{array}$ & I want John to go & John should go & John's supposed to go & It's expected that John goes \\
\hline $\begin{array}{l}\text { Modulation: } \\
\text { inclination }\end{array}$ & & Jane'll help & Jane's keen to help & \\
\hline
\end{tabular}

\subsubsection{Subjective Explicit}

The following typical examples are chosen in the original novel to help us use metaphors of modality properly in literary works.

Example one:

When Tess's father knows that his family is an aristocrat, he is proud. When meeting the boy on the road, he speaks to him in an orderly tone:

'Boy, take up that basket! I want'ee to go to an errand for me.' (Hardy, 1984:6 )

In the above underlined example, "I want to" is used as the explicitly objective metaphorical realizations of modality. The interpersonal projection in this sentence involves the speaker as projector "I want to" which expresses the inclination of the speaker to emphasize his own intentions. The tag can be expressed as "I want'ee to go to an errand for me, will you?"In this sentence, the use of "I want to"by Durbeyfield demonstrates that after knowing his family is an aristocrat, he becomes complacent and arrogant, which is closely linked with the plot to force Tess to claim kin.

Example two:

After receiving a gift from Alex, Tess's mother tries to persuade Tess to claim kin, so she says the following sentence:

'Well, there's your chance, whether or no; and I'm sure he wears a beautiful diamond ring!' (Hardy, 1984:64)

It is a metaphor of modality in the underlined example, here, the use of "I'm sure" is the same as the previous "I want to", which also refers to the subjective explicit to express metaphorical meaning. In this sentence, the interpersonal projection also involves the speaker as projector "I'm sure" while the proposition is not "I'm sure", but "does he?", this can be expressed in the tag "I'm sure he wears a beautiful diamond ring, does he?" Therefore, the original sentence is in metaphorical form which emphasizes the speaker's ideas and reflecting her mother's greedy and selfish character, which is inseparable from the tragic ending of Tess.

Example three:

Tess takes care of her family and replaces her father at work. The horse that pulls weights is so tired that it dies on the journey. Tess wants to relieve her family's burdens with her own ability. So she says the following sentences:

'Well, as I killed the horse, mother,' she said mournfully, 'I suppose I ought to do something. I don't

mind going and seeing her, but you must leave it to me about asking for help.' (Hardy, 1984:49)

In the underlined example, "I suppose" is still the same as the previous two examples: "I want to" and "I'm sure". The subjective explicit orientation of metaphors of modality is used in this sentence. The underlined "I suppose" is a subjective explicit of metaphors of modality which can be identified as a tag "I suppose I ought to do something, oughtn't I?". Here, Tess uses "I suppose" to express her own point of view which shows that as the leader of the family, Tess is brave enough to take responsibility. So she will go to claim kin without knowing Alex in the back of the novel, which leads directly to her tragic ending in the book. 


\section{Example four:}

Tess works at Alex's house and attends the dance with the maids. On her way, Tess has a dispute with them. Alex masters this opportunity and persuades Tess to go home with him. When Tess rides the horse, Alec drives the horse to an unknown place. Alex says the following sentences:

'...As to your getting to Trantridge without assistance, it is quite impossible; for, to tell the truth, dear, owing to this fog, which so disguises everything, I don't quite know where we are myself.' (Hardy, 1984:99)

The metaphor of modality is used in this sentence. The underlined "I don't quite know" is subjective explicit of metaphors of modality, which is also a direct negative of this form. Alex uses this one to emphasize that he really doesn't know where they are, however, in the context of this novel, the reader can assume that it is a trick to deceive Tess to stay there in order to take advantage of Tess, which in turn reflects his jealousy and evilness. This contrasts sharply with Tess's simple character.

Example five:

After Angel setting lover relationship with Tess, one of the difficulties they faced with their love is to persuade their parents to accept Tess because of their different social strata, so they have the following words:

'Mother, I beg your pardon. But as she really does attend Church almost every Sunday morning, and is a good Christian girl, $\underline{I}$ am sure you will tolerate any social shortcomings for the sake of that quality, and feel that I may do worse than choose her.' (Hardy, 1984:239)

It is obviously that the underlined example is the same as the previous example two but it is used by different people so it expresses different meaning. The use of "I'm sure" is the subjective explicit of metaphor of modality. In this sentence, the interpersonal projection also involves the speaker as projector "I'm sure" while the tag is different. The tag in this sentence is expressed as "I am sure you will tolerate any social shortcomings for the sake of that quality, and feel that I may do worse than choose her, will you?"

From the dialogue between Alex and his mother, we can see that his thoughts are different from other people living in Victorian times. He doesn't care about Tess's social class which is very strict in a social hierarchy, but is brave in pursuing his true love. Social class at this time is very important, so at the end of the novel Tess is willing to sacrifice herself as a murderer to save her lover.

\subsubsection{Objective Explicit}

Example one:

After Tess' parents knowing that they have a wealthy relative, they wants Tess to claim kin, so they have the following conversation:

'I've not asked her. She don't know there is any such lady relation yet. But it would certainly put her in the way of a grand marriage, and she won't say nay to going. (Hardy, 1984:36)

Different from the previous examples, the above underlined example, "it would certainly" is an objective explicit of metaphors of modality. The tag in this sentence is "It would certainly put her in the way of a grand marriage, and she won't say nay to going, isn't it?" The purpose of Tess's mother to use an explicitly objective orientation is to hide her own ideas because she is not sure whether Tess will obey their requires or not. It reflects her selfishness because she never considers her daughter's point of view. This is one of the reasons for Tess' tragic ending.

From what has been discussed above, we can draw the conclusion that modality can be used to represent a speaker's perspective and it can be identified by a tag. The subjective explicit of metaphors of modality can directly express the speaker's idea, thence, when the speaker wants to emphasize his or her own opinions, he or she can use subjective explicit when they want to hide their point of view, and make their expressions sound more objective, objective explicit can be used. In this novel, the writer uses a growing number of subjective explicit in order to let the speaker express their own ideas and highlight their characteristics to the reader.

\section{Conclusion}

Systemic Functional Linguistics holds that as a requisite part of grammatical metaphor, interpersonal metaphor is one of the vital means to reflect interpersonal meaning because the use of it is closely related to the speaker's identity and social power. Based on functional linguistics, this paper analyzes the interpersonal meaning of character dialogue in Tess of the D'Urbervilles from the perspective of interpersonal metaphor. The findings demonstrate that when analyzing the discourses of the characters in the novel, we cannot simply focus on the superficial meaning of the text, but also analyze the deep meaning and function expressed by the conversation. 
The reason is that speakers use different languages to express their standpoints because of their different personality, psychological activities and social environment in the practical application of language. No matter what the expression of sentence adopted by the author, it has a special purpose and can reflect the author's intention. Moreover, although the field of research on interpersonal metaphor has been expanded in academia at present, the analysis used in literary works is still relatively minor. By using in-depth analysis of the use of interpersonal metaphor among speakers thus reflecting their character, the author can enable readers to understand the content of the text more accurately. Most importantly, it highlights the pragmatic value of interpersonal metaphor in the analysis of literary works. Eventually, the classification and the number of interpersonal metaphor searched by the author in this novel is limited, however, more work in this direction will be continued in the future.

\section{References}

Chang, C. G. (2001). Interpersonal Grammatical Metaphor in English. Foreign Languages and Their Teaching, 7 , 6-8. (In Chinese)

Christian, M. I., Matthiessen, M., Kazuhiro, T., \& Lin, W. J. (2017). Key Terms in Systemic Functional Linguistics. Beijing: Foreign Language Teaching and Research Press.

Fang, H. M. (2001). The Complement between Interpersonal Metaphor and Speech Act Theory. Foreign Language, 4, 34-37. (In Chinese)

Halliday, M. A. K. (2017). An Introduction to Functional Grammar. Beijing: Foreign Language Teaching and Research Press.

Hardy, T. (1984). Tess of the D'urbervilles. Shang Hai: Shanghai Translation Publishing House.

Hardy, T. (1984/2003). Tess of the D'urbervilles. In G. R. Zhang (Trans). Beijing: People's Literature Publishing House, 7. (In Chinese)

Hardy, T. (1984/2006). Tess of the D'urbervilles. In D. M. Zheng (Trans). Shanghai: Shanghai Translation Publishing House, 5. (In Chinese)

Hardy, T. (1984/2013). Tess of the D'urbervilles. In Z. X. Zhao (Trans). Beijing: Modern Publishing House, 305. (In Chinese)

He, Z. Q. (2014). The Development and Problems of Grammatical Metaphor. Journal of University of Science and Technology Beijing (Social Science Edition), 4, 10-17. (In Chinese)

Hu, Z. L. (2018). The Chinese Origin and Return of Halliday's Academic Thoughts. Beijing: Foreign Language Teaching and Research Press. (In Chinese)

Hu, Z. L., Zhu, Y. S., Zhang, D. L., \& Li, Z. Z. (2017). Introduction to Systemic Functional Linguistics. Beijing: Peking University Press. (In Chinese)

Lakoff, G., \& Johnson, M. (1980). Metaphors We Live By. Chicago: The University of Chicago Press.

Liu, R. Q. (2016). Schools of Linguistics. Beijing: Foreign Language Teaching and Research Press. (In Chinese)

Peng, X. W., \& Duan, C. (2017). International Localization in China - A Summary of the Characteristics of the 16th China Systemic Functional Linguistics Academic Week. Foreign Language Research, 3, 127. (In Chinese)

Peng, X. W., Zhao, X. F., \& Zhang, Z. (2011). Introduction to Functional Grammar. Beijing: Foreign Language Teaching and Research Press. (In Chinese)

Wang, C. L. (2015). Gradation of Grammatical Metaphor: The Gradual Study of Ideational metaphor and Interpersonal Metaphor. Foreign languages and Their Teaching, 5, 49-54. (In Chinese)

Yan, S. Q. (2003). The Development of Grammatical Metaphor and Its Theoretical Significance. Journal of foreign Languages, 3, 51-57. (In Chinese)

Zhu, Y. S., Yan, S. Q., \& Miao, X. W. (2004) . An Introduction to Functional Linguistics. Shanghai: Shanghai Foreign Language Education Press. (In Chinese) 
Appendix 1. Metaphors of mood

\begin{tabular}{ccc}
\hline Metaphors of mood & Frequency & Page Number \\
\hline Declarative used as command & 13 & $47,63,40,66,80,256,76,78,98,111,469,210,281$ \\
Declarative used as question & 8 & $115,116,365,113,453,248,268,322$ \\
Interrogative used as command & 5 & $14,109,447,530,500$ \\
Interrogative used as statement & 16 & $35,511,70,254,274,327,398,426,438,543,98,464,18,256,280,290,340$ \\
\hline
\end{tabular}

Appendix 2. Metaphors of modality

\begin{tabular}{ccc}
\hline Metaphors of modality & Frequency & Page Number \\
\hline I want to & 6 & $271,283,25,248,303,499$ \\
I suppose & 21 & $63,117,267,426,75,448,499,340,541,57,66,68,97,100,346,10$ \\
& & $9,175,270$ \\
I don't know & 7 & $37,63,59,66,364,383$ \\
I think & 48 & $66,68,40,90,110,113,197,261,273,286,314,341,350,412,437$, \\
& & $463,466,234,313,317,332,540,35,73,108,364,24,53,78,99,34$ \\
& & $0,343,413,537,107,446,454,464,321,339,56,63,251,265,327$ \\
I hope & 5 & $71,67,210,275,433$ \\
I feel & 5 & $367,184,249,170$ \\
I'm sure & 12 & $39,268,289$ \\
I am afraid & 3 & 64 \\
I was quite sure & 1 & 69 \\
I declare & 1 & $488,365,96,253,283,239,253,525,489,57,435,247$ \\
I wish & 10 & 114 \\
I didn't know & 2 & 212,289 \\
I don't believe & 1 & $248,343,86$ \\
I don't think & 3 & 274,256 \\
I don't want to & 3 & 341 \\
I know & 2 & 349 \\
I was afraid & 1 & 365,450 \\
I feared & 1 & $451,453,464,499,446$ \\
I felt & 2 & 250 \\
I believe & 5 & $207,244,274,295,493,549,243,344$ \\
I assure & 1 & 100,101 \\
I cannot think & & \\
\hline
\end{tabular}

\section{Copyrights}

Copyright for this article is retained by the author(s), with first publication rights granted to the journal.

This is an open-access article distributed under the terms and conditions of the Creative Commons Attribution license (http://creativecommons.org/licenses/by/4.0/). 